\title{
UNIVERSITYOF
}

FORWARD

THINKING

WESTMINSTER ${ }^{\text {用 }}$

WestminsterResearch

http://www.westminster.ac.uk/westminsterresearch

Liver fat in adults with GH deficiency: comparison to matched controls and the effect of GH replacement

Meienberg, F., Yee, M., Johnston, DG., Cox, J., Robinson, S., Bell, J.,Thomas, EL., Taylor-Robinson, SD. and Godsland, IF.

This is the accepted version of the following article: Meienberg, F., Yee, M., Johnston, DG., Cox, J., Robinson, S., Bell, J.,Thomas, EL., Taylor-Robinson, SD. and Godsland, IF. (2016) Liver fat in adults with GH deficiency: comparison to matched controls and the effect of GH replacement Clinical Endocrinology doi:10.1111/cen.13042. The accepted version of the article was published online on 20 February 2016.

The final edited and typeset version of record will appear in the future at https://dx.doi.org/10.1111/cen.13042

The WestminsterResearch online digital archive at the University of Westminster aims to make the research output of the University available to a wider audience. Copyright and Moral Rights remain with the authors and/or copyright owners.

Whilst further distribution of specific materials from within this archive is forbidden, you may freely distribute the URL of WestminsterResearch: ((http://westminsterresearch.wmin.ac.uk/)).

In case of abuse or copyright appearing without permission e-mail repository@westminster.ac.uk 


\section{Liver fat in adults with GH deficiency: comparison to matched controls and the}

\section{effect of GH replacement}

Fabian Meienberg ${ }^{1 *}$, Michael Yee ${ }^{2 *}$, Desmond Johnston ${ }^{3}$, Jeremy Cox ${ }^{2}$, Stephen Robinson ${ }^{2}$, Jimmy D Bell $^{4}$, E. Louise Thomas ${ }^{4}$, Simon D. Taylor-Robinson ${ }^{5}$, Ian Godsland ${ }^{6}$

*authors contributed equally

${ }^{1}$ Department of Endocrinology, Diabetes and Metabolism, University Hospital Basel, Basel Switzerland;

${ }^{2}$ Metabolic Medicine Unit, St Mary's Hospital, London UK;

${ }^{3}$ Department of Medicine, Faculty of Medicine, Imperial College London, UK;

${ }^{4}$ Department of Life Sciences, Faculty of Science and Technology, University of Westminster, London UK;

${ }^{5}$ Hepatology, Department of Medicine, Faculty of Medicine, Imperial College London, London UK;

${ }^{6}$ Division of Diabetes Endocrinology and Metabolism Department of Medicine, Faculty of Medicine, Imperial College London, London UK.

Abbreviated title: Liver fat in GH deficiency

Key terms: liver fat, hepatic steatosis, growth hormone deficiency, growth hormone replacement, proton magnetic resonance spectroscopy

Word count: 4039

Number of figures and tables: 6

Corresponding author and person to whom reprint requests should be addressed:

Fabian Meienberg, MD

Department of Endocrinology, Diabetes and Metabolism

University Hospital Basel

Petersgraben 4

CH-4031 Basel

Phone: +41 613286807

Fax: +41 612655100

e-mail: fabian.meienberg@usb.ch 


\section{Disclosure Statement/Acknowledgments:}

This study was supported by a research grant from Novo Nordisk. Novo Nordisk has not influenced the content of the publication nor been involved in the study design, data collection, analysis or reporting. BRC NIHR contributed to recruitment and performance of the study.

FM received personal funding from Novo Nordisk and the Swiss National Foundation.

Clinical Trial Registration Number: NCT00774579 


\section{Abstract}

Context: Existing data regarding the association between growth hormone deficiency (GHD) and liver fat content are conflicting.

Objective: We aimed i) to assess intrahepatocellular lipid (IHCL) content in hypopituitary adults with GHD compared to matched controls and ii) to evaluate the effect of growth hormone $(\mathrm{GH})$ replacement on IHCL content.

Design: Cross-sectional comparison and controlled intervention study.

Patients, Participants: Cross-sectional comparison: 22 hypopituitary adults with GHD and 44 healthy controls matched for age, BMI, gender and ethnicity. Intervention study: 9 GHD patients starting GH replacement (GH Rx group), 9 GHD patients not starting replacement therapy (non-GH Rx group).

Intervention: Intervention study: GH replacement for 6 months in the GH Rx group, dosage was titrated to achieve normal IGF-1 levels.

Main Outcome Measures: IHCL content determined by proton magnetic resonance spectroscopy ( ${ }^{1} \mathrm{H}$ MRS). Results: Cross-sectional comparison: There was no difference in IHCL content between GHD patients and healthy controls $(1.89 \%(0.30,4.03)$ vs. $1.14 \%(0.22,2.32) ; \mathrm{p}=0.2)$, the prevalence of patients with hepatic steatosis (IHCL of $\geq 5.56 \%)$ was similar in the two groups $(22.7 \%$ vs. $15.9 \%$; chi square probability $=0.4$ ). Intervention study: The change in IHCL content over 6 months did not differ between the GH Rx group and the non-GH Rx group $(-0.63 \pm 4.53 \%$ vs. $+0.11 \pm 1.46 \%$; $\mathrm{p}=0.6)$.

Conclusions: In our study liver fat content and the prevalence of hepatic steatosis did not differ between hypopituitary adults with GHD and matched controls. In GHD patients GH replacement had no effect on liver fat content. 


\section{Introduction}

Untreated growth hormone deficiency (GHD) in adult hypopituitary patients is characterized by decreased lean body mass and increased fat mass, predominantly in the visceral compartment [1-3]. Replacement therapy with recombinant growth hormone (GH) reverses these changes in body composition [3-5].

In the general population increased visceral fat mass is associated with insulin resistance and the "metabolic syndrome' [6]. Non-alcoholic fatty liver disease (NAFLD) is defined as excessive fat in the liver in the absence of other conditions resulting in hepatic steatosis. NAFLD represents a spectrum of disease, ranging from simple steatosis to advanced disease, i.e. steatohepatitis, fibrosis and cirrhosis. In recent years insulin resistance has been widely regarded as the key mechanism in the pathogenesis of hepatic steatosis, and NAFLD has been considered to represent the hepatic component of the metabolic syndrome [7-9]. While liver biopsy is the gold standard for diagnosing NAFLD, the extent of hepatic steatosis can be accurately quantified by proton magnetic resonance spectroscopy ( ${ }^{1} \mathrm{H}$ MRS) [10].

In view of the existing association between visceral fat mass, insulin resistance and NAFLD [9] it might be expected, that patients with GHD, in whom increased visceral fat mass is a well-known feature, would also show elevated liver fat, and that GH replacement would alleviate this.

Cross-sectional data were in accord with this hypothesis [11-13]. Moreover, several case reports of hypopituitary patients report a reduction in liver fat content following GH replacement [14-16]. However, two intervention studies have reported conflicting results. A Japanese study [17] found an increased prevalence of NAFLD (diagnosed by ultrasonography) in hypopituitary GHD patients compared to matched controls, and GH replacement resulted in a significant decrease in liver enzyme levels and in an improved histological score for steatosis. The UK study by Gardner et al. [18] used ${ }^{1} \mathrm{H}$ MRS to quantify hepatic steatosis in 28 hypopituitary patients with GHD and in 24 matched controls with comparable age, BMI, gender distribution and waist circumference. In this study intrahepatocellular lipid (IHCL) content and the prevalence of NAFLD did not differ between the two groups and, in 12 GHD patients, GH replacement over 6 months did not change liver fat content. 
Uncertainties over the effects of GH replacement on liver fat in GHD patients may stem from contrasting effects of GH on insulin resistance. Immediately, GH would be expected to increase insulin resistance [19, 20], which could increase liver fat. But, in the longer term, GH-induced reductions in visceral fat would be expected to counter any GH-induced increase in insulin resistance and reduce liver fat.

In the present study, we have tested two hypotheses: 1) liver fat (measured by ${ }^{1} \mathrm{H}$ MRS) is increased in hypopituitary patients with GHD compared to age, BMI, gender and ethnicity-matched controls, and 2) the net effect of GH replacement in GHD patients over 6 months will be to reduce visceral and liver fat with little net effect on insulin resistance.

\section{Materials and Methods \\ Patients and study design}

Adult hypopituitary patients with untreated GHD were identified and recruited at the endocrine clinics of Imperial College Healthcare NHS Trust. Written informed consent was obtained from all subjects before participation and the study was approved by the NHS Research Ethics Committee of St Mary's Hospital (REC Ref Nr 07/H0712/171). The study was run in accordance with the declaration of Helsinki.

Inclusion criteria were age 20-70 years, pituitary disease with history suggestive for GHD $\geq 12$ months, unaltered replacement therapies for other hormone axes for at least 6 months. GHD had to be confirmed by performance of a stimulation test within 6 months before the study assessment. Growth hormone response was considered subnormal if $<13.26 \mathrm{mU} / \mathrm{L}$ (insulin-induced hypoglycemia) or $<7.8 \mathrm{mU} / \mathrm{L}$ (glucagon stimulation test). Exclusion criteria included alcohol consumption $>30 \mathrm{~g}$ per day in men and $>20 \mathrm{~g}$ per day in women, known hepatic disease or new diagnosis of hepatic disease at screening (all patients were screened for hepatitis B and C), GH replacement within the previous 12 months, acromegaly, Cushing's disease if not cured for at least 12 months, known diabetes mellitus, cardiac pacemaker or other contraindication to MR studies.

Between April 2008 and April 2009, we identified 26 potential recruits of whom 22 completed a full baseline assessment consisting of anthropometric measurements, biochemistry, metabolic parameters, ${ }^{1} \mathrm{H}$ MRS and 
MRI body composition measurements. All assessments were undertaken after an overnight fast. Four patients dropped out before full baseline assessment was completed, mainly as a result of claustrophobia or social commitments (Figure 1).

\section{1) Cross-sectional comparison}

Anthropometric measurements, ${ }^{1} \mathrm{H}$ MRS and MRI body composition measurements in the 22 GHD patients were compared to those of 44 age, height, weight, gender and ethnicity-matched healthy controls derived from an existing control database generated as part of an on-going study designed to look at phenotypes of adipose tissue distribution within the general population by the Robert Steiner MRI Unit, Hammersmith Campus, Imperial College London [21]. In the control subjects no data were available for biochemistry or metabolic parameters.

\section{2) Intervention study - effects of growth hormone replacement}

From the 22 GHD patients in whom baseline assessment was completed, 12 patients were started on GH replacement within 4 weeks of the baseline assessment. The initial dose of recombinant GH was 0.2-0.3 $\mathrm{mg} /$ day, titrated at monthly intervals to achieve an IGF1 level within the normal range. 9 patients were reassessed after 6 months of replacement therapy (GH Rx). The remaining 10 GHD patients recruited opted not to go on GH replacement after baseline assessment, primarily because they were not willing to perform daily injections. Nevertheless, 9 completed six months of follow-up and were re-assessed after 6 months as controls (non-GH Rx). All patients were advised to maintain the same diet and level of exercise during the study period and none took exercise on the morning of their MRS scan. Dropouts were mainly due to claustrophobia or social commitments (Figure 1). 


\section{Biochemical methods}

Measurements for liver function tests, glucose, HbA1c, insulin, lipids and pituitary hormone levels were undertaken using routine laboratory methods. IGF-1 was measured by the UK Supra-regional Assay Service by laboratories complying with a national quality control scheme.

\section{MR methods}

Intrahepatocellular lipid (IHCL), and intramyocellularlipid content (IMCL) as well as total and regional adipose tissue content were measured by ${ }^{1} \mathrm{H}$ MRS and MRI respectively on an Intera $1.5 \mathrm{~T}$ Achieva multinuclear system (Philips Medical Systems, Best, The Netherlands).

Transverse images of the liver were used to ensure accurate positioning of the $(20 \times 20 \times 20 \mathrm{~mm})$ voxel in the liver, avoiding blood vessels, the gall bladder, and fatty tissue. Spectra were obtained from the right lobe of the liver using a PRESS sequence (repetition time $1,500 \mathrm{~ms}$, echo time $135 \mathrm{~ms}$ ) without water saturation and with 128 signal averages. Liver lipid levels were expressed as percentage ratio of the $\mathrm{CH}_{2}$ lipid peak area relative to the peak area of the water resonance, after correcting for $\mathrm{T} 1$ and $\mathrm{T} 2$. We used a photographic record of the liver with the voxel position at baseline to ensure reproducibility of the voxel at follow-up.

IMCL was measured in the soleus (S-IMCL) and tibialis (T-IMCL) muscles by ${ }^{1} \mathrm{H}$ MRS. Proton MR spectra were acquired from $20 \times 20 \times 20 \mathrm{~mm}$ voxels localized to the soleus and tibialis muscles of the left calf using a PRESS sequence (repetition time $1,500 \mathrm{~ms}$, echo time $135 \mathrm{~ms}$ ). IMCL were subsequently measured, relative to total muscle creatine signal, as previously described [22].

Body composition was assessed by rapid T1-weighted magnetic resonance images (repetition time, 500 msec; echo time, $17.5 \mathrm{msec}$ ) as previously described [23]. Subjects lay in a prone position with arms straight above the head, and were scanned from fingertips to toes, acquiring 10-mm thick transverse images with 10mm thick gaps between slices throughout the body. Imaging data were analyzed using the SliceOmatic image analysis program (Tomovision, Montreal, Quebec, Canada).

Measurements were performed for total adipose tissue, subcutaneous abdominal fat, subcutaneous peripheral fat and visceral fat according to standard procedures [24]. Fat compartments were assessed for volume 
(liters), converted to mass (kilograms), and expressed as percentage of total body weight. Fat free mass was calculated by difference and expressed as percentage of total body weight.

\section{Statistics}

Data were analysed with SPSS 18.0 or STATA 8.0. Normality was assessed by Kolmogorov-Smirnov and Shapiro-Wilk tests. Normally distributed data are presented as mean and standard deviation and nonnormally distributed data as median and inter-quartile range.

Significant differences between GH treated (GH Rx) and untreated (non-GH Rx) groups at baseline and between the changes observed in the groups over 6 months were tested by between-group t-test for normally distributed variables or Mann-Whitney U test for non-normally distributed variables. Significant withingroup changes were tested by paired t-test for normally distributed variables or Wilcoxon sign rank matched pairs test for non-normally distributed variables. Pearson correlations were performed to confirm the expected associations that provided the background for our hypotheses: in GHD and control groups separately, increased total or visceral fat with increasing IHCL; and in the GHD subgroup with insulin resistance measured, increased total fat, visceral fat or IHCL with increasing insulin resistance. A significance level of $\mathrm{p}<0.05$ was adopted with no correction for multiple testing since tests were generally exploratory and choice of measures was strongly weighted by existing evidence, thus rendering the universal null hypothesis inapplicable [25].

\section{Results}

Clinical characteristics of the GHD patients are described in Table 1. They were predominantly female $(18 / 22 ; 82 \%)$ and Caucasian $(16 / 22 ; 73 \%)$. Age ranged from 39-69 years. The causes of GHD were multiple; hormone secretion in previously functioning tumors had been well controlled for at least 12 months. Pituitary hormone deficiencies ranged from single axis to pan-hypopituitarism. Ten patients were on hydrocortisone replacement; five patients on $20 \mathrm{mg} /$ day, 3 patients on $15 \mathrm{mg} /$ day, and 2 patients on $10 \mathrm{mg} /$ day. 


\section{1) Cross-sectional comparison}

The 22 GHD patients and the 44 controls ( 2 controls matched to each GHD patient) were closely matched for age, weight, height, BMI and ethnicity (Table 2). Waist/hip ratio tended to be higher in the GHD patient group. IHCL was similar in the two groups ( $1.14 \%$ vs. $1.89 \%$; $=0.2)$. Using IHCL of $\geq 5.56 \%$ as the cut-off [26], 5 out of the 22 cases (i.e. 22.7\%) and 7 out of 44 controls (i.e. 15.9\%) had NAFLD (chi square probability $=0.4$ ). T-IMCL was similar in the two groups, but S-IMCL was significantly elevated in the GHD patients compared to the controls $(15.8 \mathrm{mmol} / \mathrm{kg}$ dry weight vs. $10.5 \mathrm{mmol} / \mathrm{kg}$ dry weight; $\mathrm{p}=0.002)$. There were statistically significant differences between the two cohorts in $\%$ total adipose tissue and \% visceral adipose tissue. There were no significant differences in the other parameters assessed.

Correlation coefficients and significances in cases versus controls were, respectively: total fat with IHCL, $\mathrm{R}=0.17, \mathrm{p}=0.4$ versus $\mathrm{R}=0.41, \mathrm{p}=0.005$; visceral fat with $\mathrm{IHCL}, \mathrm{R}=0.31, \mathrm{p}=0.1$ versus $\mathrm{R}=0.42, \mathrm{p}=0.004$. In the 22 GHD cases at baseline, in whom indices of insulin resistance had been measured correlation coefficients with HOMA-IR were: total fat $\mathrm{R}=0.13$, $\mathrm{p}=0.5$; visceral fat $\mathrm{R}=0.53, \mathrm{p}=0.01$; IHCL $\mathrm{R}=0.35$, $\mathrm{p}=0.1$ and with Matsuda-IS: total fat $\mathrm{R}=-0.17, \mathrm{p}=0.4$; visceral fat $\mathrm{R}=-0.35, \mathrm{p}=0.1 ;$ IHCL $\mathrm{R}=-0.43, \mathrm{p}=0.04$.

\section{2) Intervention study}

Baseline and 6 month measurements for the 9 GHD patients starting GH replacement (GH Rx) were compared with those of the 9 GHD patients without GH replacement (non-GH Rx).

\section{Baseline differences between GH Rx and non-GH Rx groups}

The two groups were comparable in terms of age (GH Rx: $53.3 \pm 8.3$ years, non-GH Rx: $52.0 \pm 9.3$ years; $\mathrm{p}=0.76$ ) gender ( 7 female and 2 male patients in each group) and ethnicity ( 7 white Caucasians and 2 Asian Indian subjects in the GH Rx group, 7 white Caucasians, 1 Asian Indian and 1 black subject in the non-GH Rx group). At baseline, liver function tests (ALT, AST and GGT) were within normal reference ranges in all subjects; 2 patients in the GH Rx group and 3 in the non-GH Rx group had NAFLD by definition (IHCL $\geq$ 
$5.56 \%$ ) [26]. There were no significant baseline differences between the two groups in anthropometry, liver function tests, metabolic parameters or ${ }^{1} \mathrm{H}$ MRS or MRI body composition measurements (Tables 3 and 4 ).

\section{Anthropometry}

There were no between-group differences in change in weight, BMI and waist hip ratio over the 6 months. Intra-group changes were restricted to a significant reduction in waist hip ratio over time in the GH Rx group (Table 3).

\section{Liver function tests and metabolic parameters}

There were no between-group differences in change in liver function tests and metabolic parameters over the 6 months. Intra-group changes in the GH Rx group included a reduction in Matsuda-IS $(-15.0 \pm 13.1$; $\mathrm{p}=0.02)$, and increases in $\mathrm{HbA1c}(+0.17 \pm 0.21 \% ; \mathrm{p}=0.04)$, and HDL cholesterol $(+0.10 \pm 0.10 \mathrm{mmol} / \mathrm{L}$; $\mathrm{p}=0.03$ ) (Table 3). No changes were observed within the non-GH Rx group.

\section{${ }^{1} \mathrm{H}$ MR Spectroscopy, intrahepatocellular and intramyocellular lipid content}

The change in IHCL and S-IMCL over 6 months did not differ between the two groups (Table 4, Figure 2); however, the change in T-IMCL between the two groups did (GH Rx: $-2.98 \pm 5.23 \%$, non-GH Rx: $+1.27 \pm$ 2.20\%; $\mathrm{p}=0.03$ ) (Table 4, Figure 2). There were no significant intra-group changes in IHCL, SIMCL or TIMCL over 6 months. Nevertheless, in the GH Rx group, a significant correlation was noted between changes in IHCL and IHCL at baseline ( $\mathrm{rho}=-0.73, \mathrm{p}=0.02$ ), which could not be observed in the non-GH Rx Group (rho=0.33, $\mathrm{p}=0.3)$.

\section{MRI body composition measurements}

A significant between-group difference was apparent for change of $\%$ subcutaneous abdominal adipose tissue (GH Rx: $-0.76 \pm 0.71 \%$, non-GH Rx: $-0.08 \pm 0.48 \%$; $=0.02$ ) (Table 4, Figure 2) and, at borderline significance $(\mathrm{p}<0.1)$, for $\%$ total adipose tissue and $\%$ subcutaneous peripheral adipose tissue with, for each 
variable, a greater reduction in the GH Rx group. In contrast, also at borderline significance, a greater increase in \% fat-free mass was apparent in the GH Rx group $(+2.55 \pm 3.60 \%$ vs. $-0.10 \pm 2.58 \%$; $\mathrm{p}=0.09)$. There was no significant difference between the groups in the change of visceral adipose tissue.

Intra-group changes in the GH Rx group included reductions in all adipose tissue measurements and an increase in fat-free mass over 6 months (Table 4). This was not observed in the non-GH Rx group.

\section{Pituitary hormone levels}

Baseline IGF-1 values were comparable in the two groups. In the GH Rx group serum IGF-1 values were at $11.9 \pm 6.4 \mathrm{nmol} / \mathrm{L}$ at baseline and they increased by $13.4 \pm 5.7 \mathrm{nmol} / \mathrm{L}$ after 6 months $(\mathrm{p}<0.001$, for betweengroup and intra-group change). In the non-GH Rx group IGF-1 levels did not change (Table 3). Additionally, baseline serum levels of TSH (GH Rx $0.9 \pm 0.8 \mathrm{mU} / \mathrm{l}$, non-GH Rx $1.2 \pm 0.9 \mathrm{mU} / \mathrm{l}, \mathrm{p}=0.4)$ and fT4 (16.9 \pm 4.3 $\mathrm{pmol} / \mathrm{l}$ vs. $14.7 \pm 2.5 \mathrm{pmol} / \mathrm{l} ; \mathrm{p}=0.2$ ) were comparable between the two groups. Baseline prolactin levels were significantly higher in the non-GH Rx group $(268 \pm 157 \mathrm{mU} / \mathrm{l}$ vs. $118 \pm 96 \mathrm{mU} / \mathrm{l}, \mathrm{p}=0.03)$. There were no significant between-group or intra-group changes in TSH, fT4 or prolactin over 6 months. Importantly, in all patients there were no changes in established hormone replacement therapies (other than $\mathrm{GH}$ ) during the study period.

\section{Discussion}

Our first hypothesis that liver fat would be increased in hypopituitary patients with GHD compared to matched controls proved not to be the case; liver fat content and the prevalence of NAFLD assessed by ${ }^{1} \mathrm{H}$ MRS were similar in hypopituitary patients with GHD and healthy control subjects. Nevertheless, GHD patients did show increased total and visceral fat mass (as a percentage of total body mass) compared to matched controls, confirming previous data [1-3]. Our second hypothesis was that the net effect of GH replacement in GHD patients would be to reduce visceral and liver fat with little net effect on insulin resistance. In accord with our hypothesis, visceral fat fell more in the GH-treated than the untreated group and IHCL also fell but increased in the untreated group; moreover the change in two indices of insulin 
resistance showed no difference between treated and untreated groups. However, the differences in the changes in visceral and liver fat did not reach statistical significance. GH replacement increased IGF-1 levels into accepted therapeutic values, and was associated with an increase in fat-free mass and a reduction in fat mass. These findings are compatible with well-known effects of GH replacement therapy [3-5] and suggest that our observation period was adequate to observe potential changes in liver fat.

Data on GHD and liver fat content are conflicting. Our results are consistent with those from a previous UK study by Gardner et al. [18] but are contrary to those from the Japanese study by Nishizawa et al. [17]. In the UK study 12 GHD patients underwent GH replacement therapy over 6 months with no effect on liver fat but significant reductions in both visceral and subcutaneous fat mass. As in our study, liver fat content was precisely quantified using ${ }^{1} \mathrm{H}$ MRS. In contrast, the Japanese study employed the semi-quantitative technique of ultrasonography [17] and demonstrated a significantly elevated prevalence of NAFLD in 66 hypopituitary patients with GHD compared to 83 healthy age-, gender-, and BMI-matched controls (77\% vs. 12\%, $\mathrm{p}<0.001)$. In the Japanese study no imaging of the liver was performed after initiation of GH replacement. However, GH replacement therapy in 19 patients for 6 months resulted in a significant reduction of serum liver enzyme concentrations, parameters that remained unchanged in our study and the previous UK study. Moreover, in the 5 of the GHD patients who had histologically confirmed NASH, GH replacement for 6-12 months significantly improved histological steatosis and fibrosis scores.

The GHD patients in our study were generally similar to those in the previous UK study [18], although our cohort displayed a higher percentage of female participants (82\% vs. $29 \%$ ) and a lower prevalence of NAFLD (23\% in GHD patients, $16 \%$ in controls vs. $32 \%$ in GHD patients, $50 \%$ in controls), the latter probably reflecting the lower propensity of females towards NAFLD compared to males. It should be noted, however, that in our cohort males did not show significantly higher liver fat compared to females, even after adjusting for BMI and age, nor did the change in liver fat differ between men and women. In the Japanese study, gender distribution was equal, patients were on average 4 years younger, and BMI was 3-4 points lower than in our study, the mean IGF-1 level was comparable to the levels in our study. This and the fact that virtually all cross-sectional data and case reports suggesting an association between GHD and NAFLD 
originate from Japan $[12,15,16]$, China [14] and Korea [11] raises the question whether the effects of GHD on liver fat may vary according to ethnicity.

Other factors that might have contributed to our failure to detect a statistically significant reduction in liver fat under GH replacement include the relatively low numbers studied, the low prevalence of NAFLD in the study groups plus a possible underlying confounding influence of the negative effect of GH on insulin sensitivity (see below).

As mentioned, the absent effect of GH replacement on liver fat in our study and in the previous UK study might be due to the low baseline liver fat content (medians $2.13 \%$ and $2.8 \%$, respectively) and the relatively few patients with NAFLD (2/9 and 4/12, respectively), which is in contrast to the high prevalence of NAFLD (77\%) in the Japanese study. Despite small numbers, patients in our study who had higher baseline liver fat content did indeed show a more pronounced decrease in liver fat following GH replacement, an effect that was not present in our non-GH Rx group and, though weaker, a similar relationship was apparent in the previous UK study. Therefore, it is possible that GH replacement might only reduce liver fat content in the subgroup of GHD patients with NAFLD. Moreover, we know from lifestyle studies in the general population that changes in liver fat are directly proportional to the starting level of liver fat [27].

Increased fat accumulation, particularly in the visceral compartment is a well-documented feature of GHD in adults [1-3] and this has been confirmed in our study. In the general population increased visceral fat mass is associated with the metabolic syndrome, and both are associated with NAFLD. It is therefore unexpected that in our study, liver fat content was not increased, suggesting that the relationship between visceral and liver fat may be different in GHD. In support of this, correlations between IHCL and MRI regional fat measures in our cross-sectional comparison were generally stronger in the control group than among the cases and this was also reported in the previous UK study [18]. A further unexpected finding, given the lipolytic effects of GH, was the lack of effect on free fatty acid (FFA) and triglyceride concentrations in response to GH replacement. There is evidence for an increase in fasting FFA concentrations in response to 
GH [28], and for increased fasting triglycerides [29, 30]. However, diurnal FFA concentrations may not be increased [28] and increases in triglycerides do not appear to persist long-term [29, 31]. Inconsistencies, both in the relationships between visceral and liver fat and in effects on lipid levels in response to GH treatment may stem from a biphasic effect of $\mathrm{GH}$ on insulin resistance with deterioration within the first months of treatment, then an improvement in the long-term. Hence, changes in visceral fat mass and insulin resistance might not evolve in parallel during the first months of GH replacement therapy and effects on lipids may vary with time.

An effect of GH replacement was, nevertheless, apparent in our observation of a statistically significant increase in HDL cholesterol and HbA1c levels, and a significant decrease in the Matsuda insulin sensitivity index (intra-group changes only), findings that are compatible with some but not all previous studies [19, 20, 32].

The previous UK study found no difference in intramyocellular lipid content between GHD patients and controls, nor did GH replacement affect it [18]. By contrast, we observed significantly higher soleus muscle (a representative oxidative muscle) lipid content in GHD patients compared with matched controls and GH replacement reduced anterior tibialis muscle (a glycolytic muscle) lipid content. Muscle lipid content is responsive to diet and acutely responsive to exercise $[33,34]$ and, although patients attended after an overnight fast and received general instructions regarding maintenance of constant dietary and exercise habits during the trial, details of lifestyle were not recorded. Given the lack of a precedent for these observations, the small numbers studied and the large number of variables considered in our study these may be chance findings. Dedicated studies of muscle lipid response to GH treatment will be needed to resolve these issues, although current evidence suggests that IMCL has less influence on insulin resistance than previously supposed [35].

In our study replacement therapy of other pituitary hormones remained stable over the study period making hormonal factors influencing liver fat - other than GH - very unlikely. Although this has not been 
extensively studied, any degree of over-replacement with glucocorticoids might induce hepatic steatosis. Our patients were on a maximum daily replacement of $20 \mathrm{mg}$ hydrocortisone, which is similar to the cortisol secretion rate in healthy subjects [36]. In the study by Niwhizawa et al. over-replacement is unlikely as the average dose of cortisol replacement in the patients with NAFLD was $0.19 \pm 0.14 \mathrm{mg} / \mathrm{kg} \mathrm{BW}$. Nevertheless, given that body fat measures were the primary outcome variables in this study, specific instructions regarding taking hormone replacement on the morning of their measurements were not given to patients. Some variability in biochemical measurements may, therefore, have resulted from variation in, for example, timing of hydrocortisone use.

The most important limitation of our study is the relatively small number of subjects, particularly in the intervention study. Furthermore, as we did not perform liver biopsies, we cannot draw conclusions about the effect of GH replacement on inflammation or fibrosis. Nevertheless, we used a very precise method to assess for hepatic steatosis, included a well-matched control group in our cross-sectional comparison, and performed a controlled intervention with GH replacement.

In conclusion, we have demonstrated that hepatic steatosis is not increased in hypopituitary adults with GHD compared to healthy controls. Furthermore GH replacement therapy did not alter liver fat content in these patients. Reasons for the discrepancy between data from the UK and data from Asian origin regarding this issue might be elucidated by further studies. 


\section{References}

1. De Boer, H., et al., Body composition in adult growth hormone-deficient men, assessed by anthropometry and bioimpedance analysis. J Clin Endocrinol Metab, 1992. 75(3): p. 833-7.

2. Rosen, T., et al., Increased body fat mass and decreased extracellular fluid volume in adults with growth hormone deficiency. Clin Endocrinol (Oxf), 1993. 38(1): p. 63-71.

3. Molitch, M.E., et al., Evaluation and treatment of adult growth hormone deficiency: an Endocrine Society clinical practice guideline. J Clin Endocrinol Metab, 2011. 96(6): p. 1587609.

4. Beauregard, C., et al., Growth hormone decreases visceral fat and improves cardiovascular risk markers in women with hypopituitarism: a randomized, placebo-controlled study. J Clin Endocrinol Metab, 2008. 93(6): p. 2063-71.

5. Hazem, A., et al., Body composition and quality of life in adults treated with GH therapy: a systematic review and meta-analysis. Eur J Endocrinol, 2012. 166(1): p. 13-20.

6. Eckel, R.H., S.M. Grundy, and P.Z. Zimmet, The metabolic syndrome. Lancet, 2005. 365(9468): p. 1415-28.

7. McCullough, A.J., Pathophysiology of nonalcoholic steatohepatitis. J Clin Gastroenterol, 2006. 40 Suppl 1: p. S17-29.

8. Chalasani, N., et al., The diagnosis and management of non-alcoholic fatty liver disease: practice Guideline by the American Association for the Study of Liver Diseases, American College of Gastroenterology, and the American Gastroenterological Association. Hepatology, 2012. 55(6): p. 2005-23.

9. Yki-Jarvinen, $\mathrm{H}$., Non-alcoholic fatty liver disease as a cause and a consequence of metabolic syndrome. Lancet Diabetes Endocrinol, 2014. 2(11): p. 901-10.

10. Clark, J.M., F.L. Brancati, and A.M. Diehl, Nonalcoholic fatty liver disease. Gastroenterology, 2002. 122(6): p. 1649-57.

11. Hong, J.W., et al., Metabolic parameters and nonalcoholic fatty liver disease in hypopituitary men. Horm Metab Res, 2011. 43(1): p. 48-54.

12. Ichikawa, T., et al., Non-alcoholic steatohepatitis and hepatic steatosis in patients with adult onset growth hormone deficiency. Gut, 2003. 52(6): p. 914.

13. Nyenwe, E.A., et al., Nonalcoholic Fatty liver disease and metabolic syndrome in hypopituitary patients. Am J Med Sci, 2009. 338(3): p. 190-5.

14. Tai, T.S., S.Y. Lin, and W.H. Sheu, Metabolic effects of growth hormone therapy in an Alstrom syndrome patient. Horm Res, 2003. 60(6): p. 297-301.

15. Takano, S., et al., Effect of growth hormone on fatty liver in panhypopituitarism. Arch Dis Child, 1997. 76(6): p. 537-8.

16. Takahashi, Y., et al., Growth hormone reverses nonalcoholic steatohepatitis in a patient with adult growth hormone deficiency. Gastroenterology, 2007. 132(3): p. 938-43.

17. Nishizawa, $\mathrm{H}$., et al., Nonalcoholic fatty liver disease in adult hypopituitary patients with $\mathrm{GH}$ deficiency and the impact of GH replacement therapy. Eur J Endocrinol, 2012. 167(1): p. 67-74.

18. Gardner, C.J., et al., Hepatic steatosis, GH deficiency and the effects of GH replacement: a Liverpool magnetic resonance spectroscopy study. Eur J Endocrinol, 2012. 166(6): p. 9931002.

19. Gazzaruso, C., et al., Cardiovascular risk in adult patients with growth hormone (GH) deficiency and following substitution with GH--an update. J Clin Endocrinol Metab, 2014. 99(1): p. 18-29.

20. Moller, N. and J.O. Jorgensen, Effects of growth hormone on glucose, lipid, and protein metabolism in human subjects. Endocr Rev, 2009. 30(2): p. 152-77.

21. Thomas, E.L., et al., The missing risk: MRI and MRS phenotyping of abdominal adiposity and ectopic fat. Obesity (Silver Spring), 2012. 20(1): p. 76-87. 
22. Rico-Sanz, J., et al., Diversity in levels of intracellular total creatine and triglycerides in human skeletal muscles observed by (1)H-MRS. J Appl Physiol (1985), 1999. 87(6): p. 2068-72.

23. Thomas, E.L., et al., Hepatic triglyceride content and its relation to body adiposity: a magnetic resonance imaging and proton magnetic resonance spectroscopy study. Gut, 2005. 54(1): p. 122-7.

24. Thomas, E.L., et al., Magnetic resonance imaging of total body fat. J Appl Physiol (1985), 1998. 85(5): p. 1778-85.

25. Perneger, T.V., What's wrong with Bonferroni adjustments. BMJ, 1998. 316(7139): p. 12368.

26. Browning, J.D., et al., Prevalence of hepatic steatosis in an urban population in the United States: impact of ethnicity. Hepatology, 2004. 40(6): p. 1387-95.

27. Johnson, N.A., et al., Aerobic exercise training reduces hepatic and visceral lipids in obese individuals without weight loss. Hepatology, 2009. 50(4): p. 1105-12.

28. Kousta, E., et al., The effects of growth hormone replacement therapy on overnight metabolic fuels in hypopituitary patients. Clin Endocrinol (Oxf), 2000. 52(1): p. 17-24.

29. Riedl, M., et al., The increased insulin sensitivity in growth hormone-deficient adults is reduced by growth hormone replacement therapy. Eur J Clin Invest, 2000. 30(9): p. 771-8.

30. Trepp, R., et al., Effect of growth hormone (GH) on fasting and postprandial metabolism in GH deficiency. Exp Clin Endocrinol Diabetes, 2010. 118(9): p. 596-601.

31. Johnston, D.G., et al., Long-term effects of growth hormone therapy on intermediary metabolism and insulin sensitivity in hypopituitary adults. J Endocrinol Invest, 1999. 22(5 Suppl): p. 37-40.

32. Appelman-Dijkstra, N.M., et al., Long-term effects of recombinant human GH replacement in adults with GH deficiency: a systematic review. Eur J Endocrinol, 2013. 169(1): p. R1-14.

33. Bucher, J., et al., The effect of a single $2 h$ bout of aerobic exercise on ectopic lipids in skeletal muscle, liver and the myocardium. Diabetologia, 2014. 57(5): p. 1001-5.

34. Lara-Castro, C., et al., Effects of short-term very low-calorie diet on intramyocellular lipid and insulin sensitivity in nondiabetic and type 2 diabetic subjects. Metabolism, 2008. 57(1): p. 1-8.

35. Amati, F., et al., Skeletal muscle triglycerides, diacylglycerols, and ceramides in insulin resistance: another paradox in endurance-trained athletes? Diabetes, 2011. 60(10): p. 2588-97.

36. Kraan, G.P., et al., The daily cortisol production reinvestigated in healthy men. The serum and urinary cortisol production rates are not significantly different. J Clin Endocrinol Metab, 1998. 83(4): p. 1247-52. 
Table 1 Clinical characteristics of the 22 hypopituitary patients with GHD who underwent full baseline assessment

\begin{tabular}{|c|c|c|c|c|c|c|c|c|c|c|}
\hline \multirow{2}{*}{$\begin{array}{c}\text { Cas } \\
\mathrm{e} \\
\text { No }\end{array}$} & \multirow{2}{*}{$\begin{array}{l}\text { Age } \\
(y r)\end{array}$} & \multirow[t]{2}{*}{ Sex } & \multirow[t]{2}{*}{ Diagnosis } & \multirow{2}{*}{$\begin{array}{c}\text { Time } \\
\text { since } \\
\text { diagnosi } \\
\text { s (years) }\end{array}$} & \multirow[b]{2}{*}{ Treatment } & \multicolumn{5}{|c|}{ Hormone replacement therapies } \\
\hline & & & & & & $\begin{array}{l}\text { Cortisol } \\
\text { (mg/day) }\end{array}$ & $\begin{array}{c}\text { T4 } \\
\text { ( } \mu \mathrm{g} / \text { day) }\end{array}$ & SHRT & DDAVP & $\begin{array}{c}\text { startin } \\
\mathbf{g} \\
\mathrm{rGH}\end{array}$ \\
\hline$\overline{1}$ & 41 & $\mathrm{M}$ & Prolactinoma & 8 & $\overline{D A}$ & 0 & 0 & 0 & 0 & + \\
\hline 2 & 51 & $\mathrm{~F}$ & PRL\&GH secreting pituitary adenoma & 22 & $\mathrm{~s}$ & 0 & 0 & 0 & 0 &,$+ \mathrm{DO}$ \\
\hline 3 & 65 & $\mathrm{~F}$ & Prolactinoma & 27 & $\mathrm{~S}$ & 0 & 0 & 0 & 0 &,$+ \mathrm{DO}$ \\
\hline 4 & 60 & $\mathrm{~F}$ & Prolactinoma & 31 & $\mathrm{R}$ & 0 & 125 & 0 & 0 & + \\
\hline 5 & 52 & $\mathrm{~F}$ & Idiopathic GHD and hypogonadism & 35 & - & 0 & 100 & + & 0 & + \\
\hline 6 & 47 & $\mathrm{~F}$ & Empty sella & 1 & - & 15 & 100 & + & 0 & + \\
\hline 7 & 62 & $\mathrm{~F}$ & NFPA & 8 & $\mathrm{~S}, \mathrm{R}$ & 0 & 100 & 0 & 0 & + \\
\hline 8 & 47 & $\mathrm{~F}$ & M. Cushing & 3 & $\mathrm{~s}$ & 10 & 0 & 0 & 0 & + \\
\hline 9 & 47 & $\mathrm{~F}$ & Idiopathic GHD and hypogonadism & 10 & - & 10 & 0 & 0 & 0 & + \\
\hline 10 & 60 & $\mathrm{M}$ & Pituitary apoplexy & 1 & $\mathrm{~s}$ & 20 & 100 & + & 0 & + \\
\hline 11 & 41 & $\mathrm{~F}$ & Sheehan syndrome & 1 & - & 20 & 100 & 0 & 0 &,$+ \mathrm{DO}$ \\
\hline 12 & 64 & $\mathrm{~F}$ & NFPA & 30 & $\mathrm{R}$ & 0 & 100 & 0 & 0 & + \\
\hline 13 & 54 & $M$ & NFPA & 3 & $\mathrm{~s}$ & 20 & 50 & + & 0 & - \\
\hline 14 & 58 & $\mathrm{~F}$ & NFPA & 3 & $\mathrm{~S}, \mathrm{R}$ & 0 & 0 & 0 & 0 & - \\
\hline 15 & 47 & $M$ & NFPA & 5 & $\mathrm{~S}, \mathrm{R}$ & 15 & 0 & + & 0 & - \\
\hline
\end{tabular}




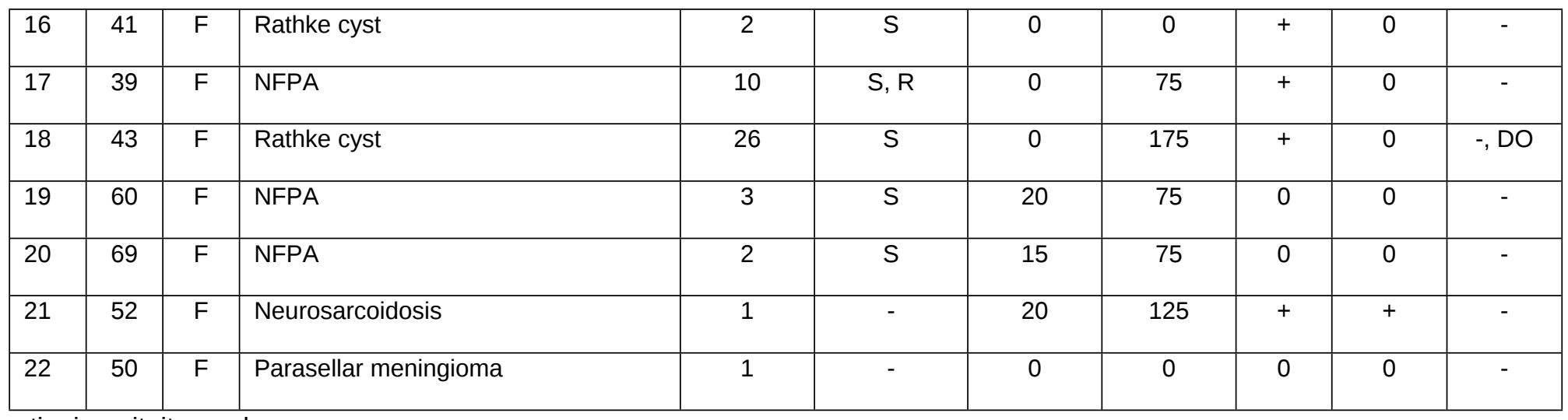

NFPA, Non-functioning pituitary adenoma

DA, current dopamine agonist treatment; S, pituitary surgery; R, pituitary radiotherapy

Cortisol (hydrocortisone) dose is total in mg/day, Thyroxine (T4) dose is $\mu \mathrm{g} /$ day

SHRT, sex hormone replacement therapy, indicated as +/0; various SHRT preparations in men and women.

DDAVP indicated as $+/ 0$, in patients with diabetes insipidus.

$\mathrm{rGH}$, recombinant growth hormone, indicated as $+/$ - if patients started $\mathrm{GH}$ replacement after baseline assessment.

DO, patient dropped out during the intervention study, i.e. did not undergo re-assessment after 6 months. 
Table 2 Cross-sectional comparison: growth hormone-deficient (GHD) patients compared with height, weight, age, gender and ethnicity-matched apparently healthy controls (2 controls matched to each $\mathrm{GH}$-deficient patient) for anthropometry, in vivo ${ }^{1} \mathrm{H} \mathrm{MR}$ spectroscopy and full MRI body composition measurements (percent fat masses are expressed relative to total body weight).

\begin{tabular}{lccc}
\hline & Controls & GHD patients & $p$ \\
& $(\mathrm{n}=44)$ & $(\mathrm{n}=22)$ & \\
\hline Females / males $(\mathrm{n})$ & $36 / 8$ & $18 / 4$ & 1.0 \\
Caucasian/South Asian origin/African & & & \\
Caribbean/Oriental (n) & $38 / 4 / 2 / 0$ & $16 / 2 / 3 / 1$ & 0.4 \\
Age (years) & $51.6(8.9)$ & $52.2(8.8)$ & 0.8 \\
Weight (kg) & $75.4(11.9)$ & $76.8(13.7)$ & 0.7 \\
Height (m) & $1.64(0.09)$ & $1.64(0.08)$ & 0.9 \\
BMI (kg/m²) & $27.9(4.3)$ & $28.5(5.0)$ & 0.6 \\
Waist/Hip Ratio* & $0.86(0.10)$ & $0.90(0.06$ & 0.08 \\
Intrahepatocellular lipid (\%) & $1.14(0.22,2.32)$ & $1.89(0.30,4.03)$ & 0.2 \\
Soleus intramyocellular lipid (\%) & $10.5(7.9,13.9)$ & $15.8(11.9,20.8)$ & 0.002 \\
Tibialis intramyocellular lipid (\%) & $6.5(5.0,8.9)$ & $6.3(4.7,9.7)$ & 0.7 \\
\% total adipose tissue & $38.6(8.9)$ & $42.2(7.6)$ & $\mathbf{0 . 0 4}$ \\
\% subcutaneous abdominal & $9.0(3.1)$ & $9.8(2.5)$ & 0.2 \\
\% subcutaneous peripheral & $22.6(5.5)$ & $24.3(5.8)$ & 0.2 \\
\% visceral adipose tissue & $3.8(1.6)$ & $4.6(1.2)$ & $\mathbf{0 . 0 3}$ \\
\% fat-free mass & $61.4(8.9)$ & $57.8(7.6)$ & 0.1 \\
\hline
\end{tabular}

Mean (SD) for normally distributed variables or median (IQ range) for non-normally distributed variables are shown. Significant differences between the groups were tested by between-group ttest for normally distributed variables or Mann-Whitney $U$ test for non-normally distributed variables.

* waist hip ratio was recorded in 32 controls. 
Table 3 Growth hormone replacement trial: Anthropometry, biochemistry and metabolic parameters in 9 growth hormone deficient (GHD) patients were studied prior to and after 6 months taking GH. Changes were compared with those in 9 GHD patients, also studied at baseline and after 6 months, but receiving no GH replacement.

\begin{tabular}{|c|c|c|c|c|c|}
\hline & \multicolumn{2}{|c|}{ GH treated } & \multicolumn{2}{|c|}{ untreated } & \multirow[b]{2}{*}{$\begin{array}{l}\text { between-group } \\
\text { change } \\
\text { significance }\end{array}$} \\
\hline & baseline & $\begin{array}{c}\text { change after } 6 \\
\text { months }\end{array}$ & baseline & $\begin{array}{c}\text { change after } 6 \\
\text { months }\end{array}$ & \\
\hline Weight (kg) & $79.7(17.1)$ & $+0.24(2.54)$ & $78.7(8.7)$ & $+0.14(1.35)$ & 0.9 \\
\hline BMI $\left(\mathrm{kg} / \mathrm{m}^{2}\right)$ & $29.1(6.6)$ & $+0.09(0.87)$ & $29.3(3.5)$ & $+0.06(0.51)$ & 0.9 \\
\hline Waist hip ratio & $0.90(0.04)$ & $-0.02(0.03)^{0.04}$ & $0.90(0.08)$ & $+0.01(0.06)$ & 0.1 \\
\hline IGF-1 (nmol/L) & $11.9(6.4)$ & $+13.4(5.7)<0.001$ & $10.6(6.5)$ & $-0.15(2.61)$ & $<0.001$ \\
\hline $\operatorname{ALT}(\mathrm{U} / \mathrm{L})$ & $28.7(9.1)$ & $-1.2(8.3)$ & $24.1(12.7)$ & $-2.0(12.5)$ & 0.8 \\
\hline AST (U/L) & $25.3(5.3)$ & $+2.0(5.1)$ & $24.6(10.4)$ & $-0.44(12.1)$ & 0.6 \\
\hline GGT (U/L) & $36.6(29.8)$ & $-5.5(14.3)$ & $23.9(9.4)$ & +3.2(10.6) & 0.1 \\
\hline fasting glucose & $5.22(0.56)$ & $-0.14(0.50)$ & $4.78(0.46)$ & $+0.26(0.56)$ & 0.1 \\
\hline fasting insulin & $9(4,12)$ & $+0.88(5.9)$ & $5(4,11)$ & $+0.33(5.6)$ & 0.8 \\
\hline HOMA-IR & $1.84(0.86,2.62)$ & $+0.25(1.61)$ & $0.95(0.84,2.49)$ & $+0.16(1.26)$ & 0.9 \\
\hline Matsuda-IS & $62.7(48.3,110.3)$ & $-15.0(13.1)^{0.02}$ & $144(53,168)$ & $-23.9(69.2)$ & 0.7 \\
\hline $\mathrm{HbA1c}(\%)$ & $5.9(0.4)$ & $+0.17(0.21)^{0.04}$ & $5.8(0.4)$ & $+0.04(0.20)$ & 0.2 \\
\hline Cholesterol (mmol/L) & $4.79(0.77)$ & $+0.16(0.59)$ & $5.03(0.92)$ & $-0.09(0.66)$ & 0.4 \\
\hline HDL cholesterol (mmol/L) & $1.43(0.22)$ & $+0.10(0.10)^{0.03}$ & $1.53(0.22)$ & $+0.08(0.26)$ & 0.8 \\
\hline Triglycerides (mmol/L) & $1.34(0.80,2.03)$ & $+0.13(0.42)$ & $1.24(0.77,1.45)$ & $-0.09(0.46)$ & 0.7 \\
\hline
\end{tabular}


Free fatty acids $(\mathrm{meq} / \mathrm{L}) \quad 0.66(0.26) \quad+0.01(0.23) \quad 0.76(0.22) \quad+0.03(0.26)$

0.3

Mean (SD) for normally distributed variables or median (IQ range) for non-normally distributed variables are shown. Significant differences between GH treated and untreated groups at baseline and between the changes observed in the groups over 6 months were tested by between-group t-test for normally distributed variables or Mann-Whitney $U$ test for non-normally distributed variables. Significant within-group changes were tested by paired t-test for normally distributed variables or Wilcoxon sign rank matched pairs test for non-normally distributed variables. No significant differences between the groups at baseline were observed. Significant within-group changes at $p<0.1$ are shown as actual value superscripts in the 'change after 6 months' column. 
Table 4 Growth hormone replacement trial: In vivo ${ }^{1} \mathrm{H}$ MR spectroscopy and full MRI body composition measurements (percent fat masses are expressed relative to total body weight) in 9 growth hormone deficient (GHD) patients were studied prior to and after 6 months taking GH. Changes were compared with those in 9 GHD patients, also studied at baseline and after 6 months, but receiving no GH replacement.

\section{GH treated}

baseline

\section{untreated}

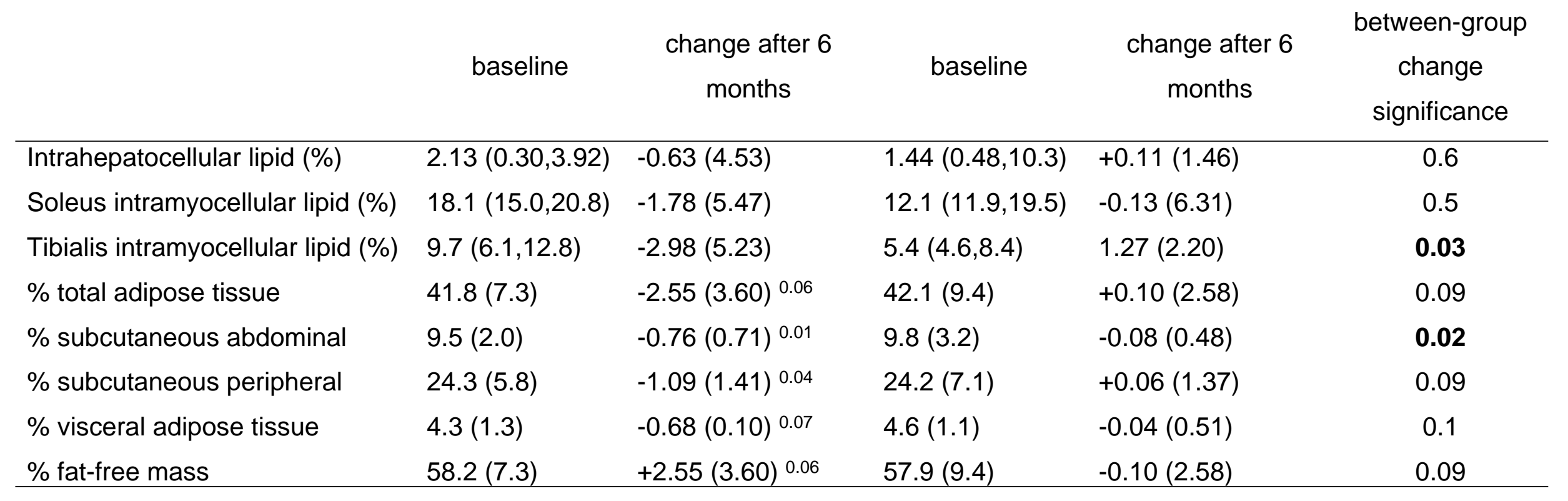

Mean (SD) for normally distributed variables or median (IQ range) for non-normally distributed variables are shown. Significant differences between GH treated and untreated groups at baseline and between the changes observed in the groups over 6 months were tested by between-group t-test for normally distributed variables or Mann-Whitney U test for non-normally distributed variables. Significant within-group changes were tested by paired t-test for normally distributed variables or Wilcoxon sign rank matched pairs test for non-normally distributed variables. No significant differences between the groups at baseline were observed. Significant within-group changes at $p<0.1$ are shown as actual value superscripts in the 'change after 6 months' column. 
Figure 1 - CONSORT diagram for patient recruitment, allocation and follow-up

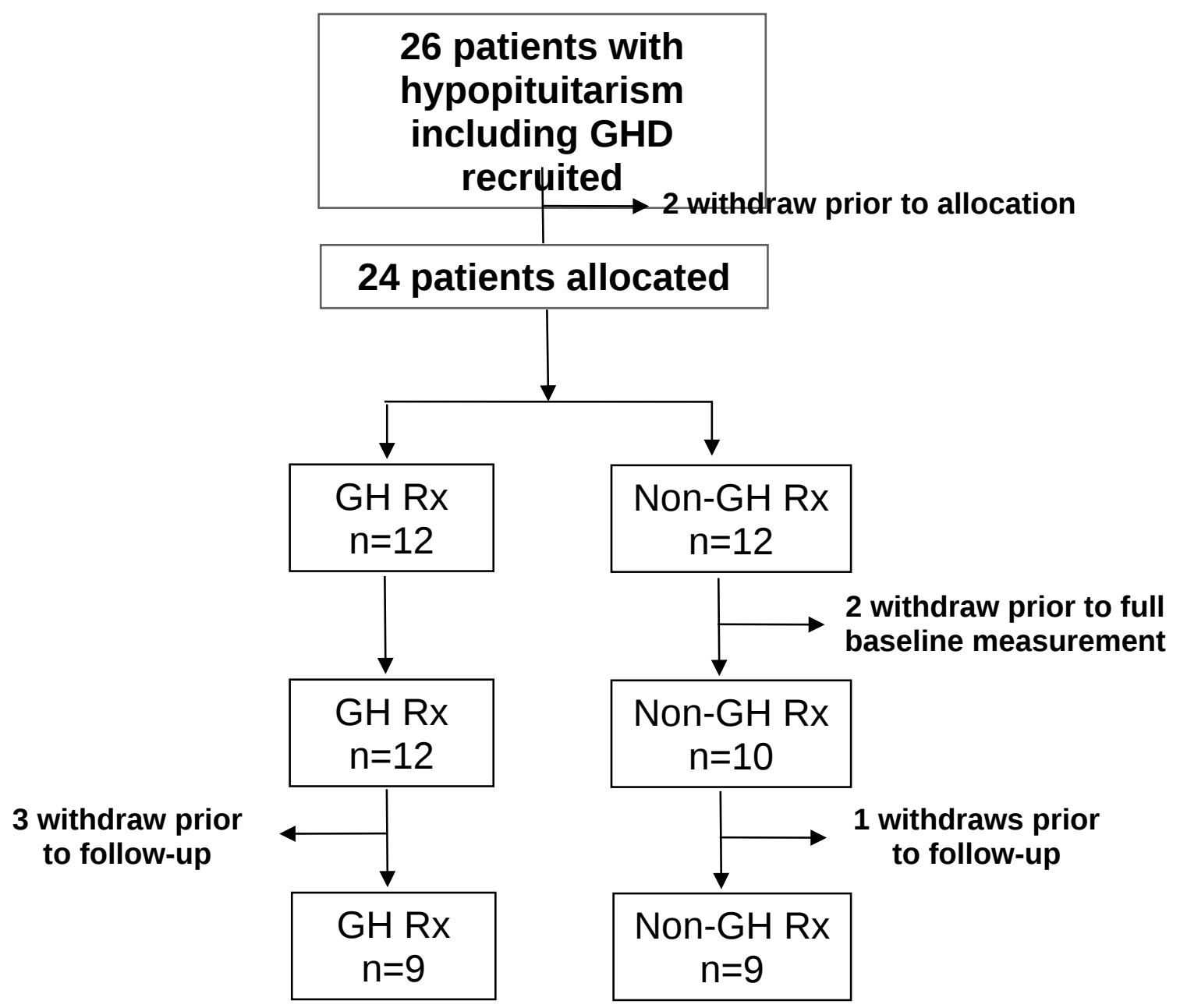


Figure 2 - Growth hormone replacement trial: \% changes from baseline of intrahepatocellular lipid (IHCL), tibialis intramyocellular lipid (TIMCL), and \% subcutaneous abdominal fat (\%SC ABDO). 9 growth hormone deficient (GHD) patients were studied prior to and after 6 months taking GH replacement therapy (GH treated). Nine control patients were studied at baseline and after 6 months without receiving GH replacement therapy (untreated). $p$-values indicate significance for between-group difference.

\section{dIHCL}

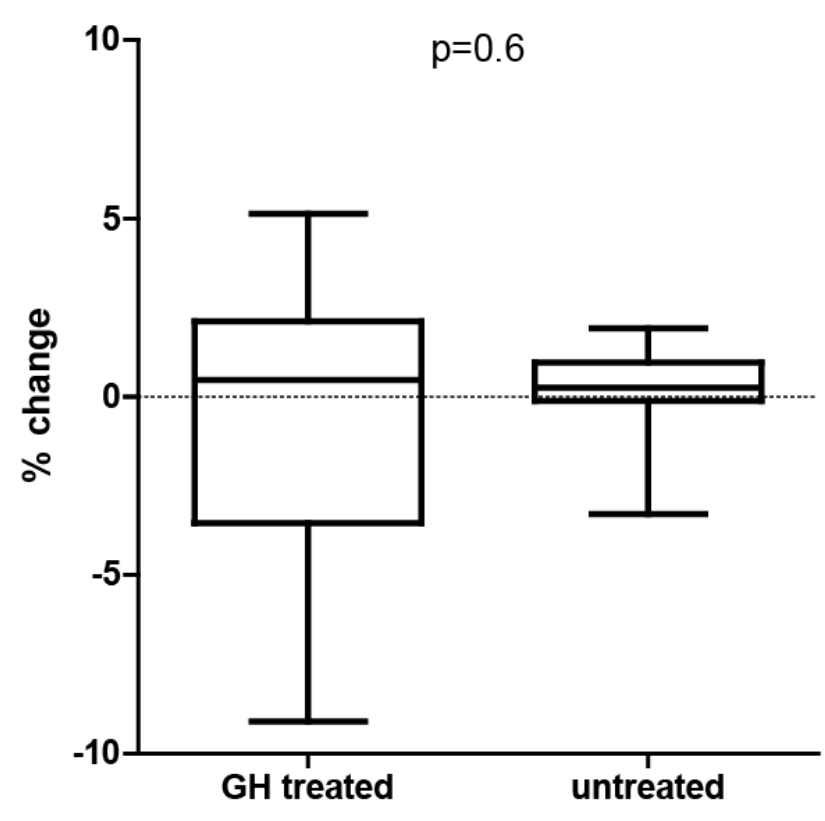

dTIMCL

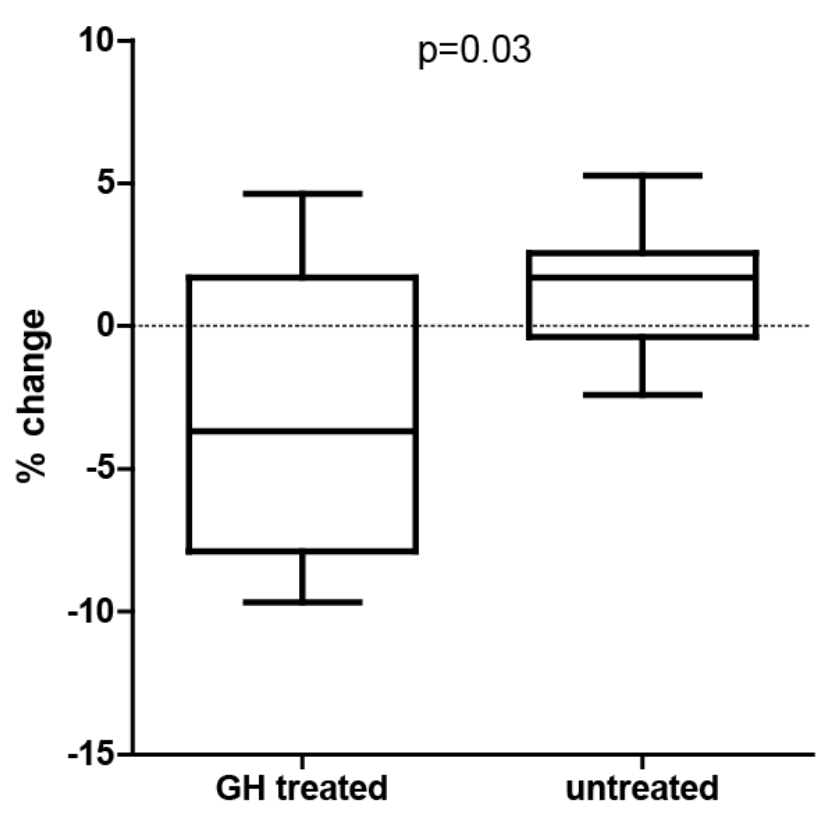

d\%SC ABDO

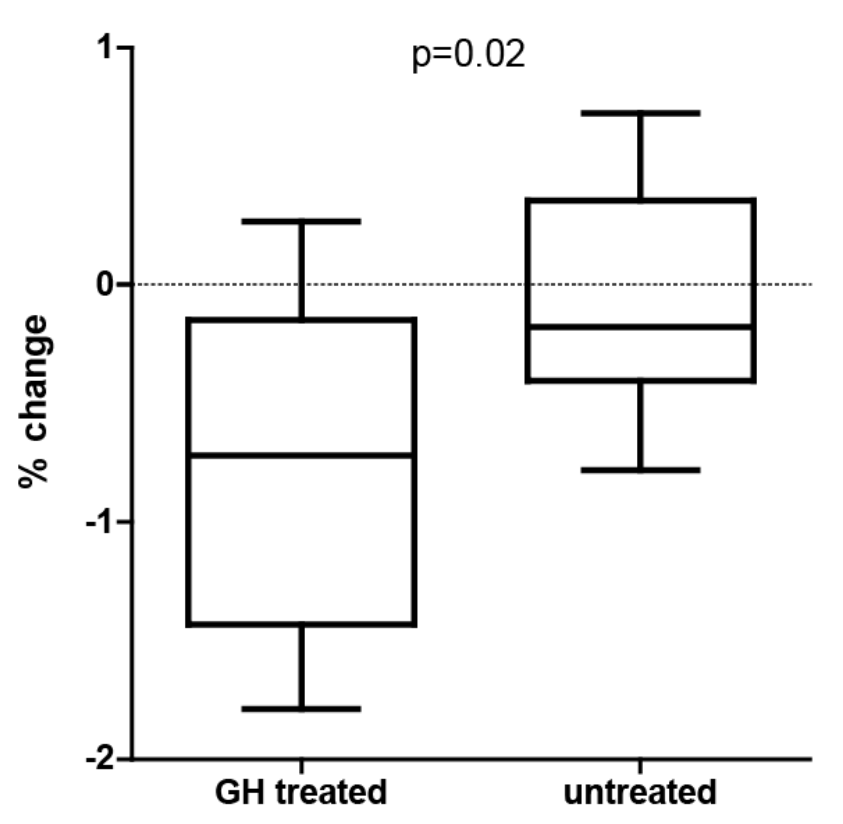

